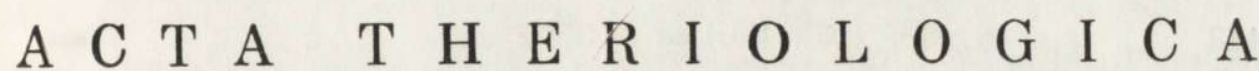

VOL. XIII, 27: $447-452$.

BIAEOWIEŻA

30.X.1968

\author{
Gheorghe B URLACU \& Gheorghe F ĂGET
}

\section{An Equipment for Efiort Metabolism Recording in Laboratory Animals}

[With 2 Figs.]

\begin{abstract}
In order to investigate continously the effort energy metabolism in laboratory animals, at various moments during a effort of varying intensity and to dispense with the electrical excitements, we designed on equipment consisting of a torus-shaped revolving chamber, provided with radial pipes converging to a tight-hubb, which secures the air input and output by means of two admission and evacuation pipes. The rotary motion of the chamber is performed by pinions geared to an adjustable speed engine. The air expired by the animal during the experiment is sucked up by a pump and driven back into an interferometer, where the percentage of $\mathrm{CO}_{2}$ and the deficit of $\mathrm{O}_{2}$ in the analysed air may be read, after the air being washed in several absorption vessels.
\end{abstract}

The effort metabolism in laboratory animals is usually ascertained by different devices provided with rolling carpets, mobile cords, or revolving chambers. There are also equipments with water tubs where the immersed animals are obliged to swim and they must therefore take pains to remain on the water surface.

All these equipments show some disadvantages; the rolling carpets and the mobile cords require special electrical devices for stimulate the animals when they show a tendency to rest, while the revolving chambers have sometimes a poor tightness between the actually mobile chambers and the fixed pipes leading to the gas analyser $\left(\mathrm{CO}_{2}\right.$ and $\left.\mathrm{O}_{2}\right)$. A further inconvenience is the rather large volume of the respiratory chambers as compared to the size of the straining animal, thus waking more laborious uninterrupted determination of the effort metabolism at different moments. As far as the water tubs are concerned, they require special thermoregulatory conditions for an accurate effort metabolism recording. 
In order to avoid these shortcomings, and particulary to obtain a decrease in the air volume where the animals are moving and to dispense with the electrical excitements mentioned above, we designed an equipment consisting of a torus-shaped revolving chamber, provided with radial pipes converging to a tight hubb, which secures the air input and output by means of two admission and evacuation pipes. The rotary motion of the chambers is performed by pinions geared to an adjustable speed engine. The air expired by the animal during the experiment is sucked up by a pump and driven back into an interferometer, where the percentage of $\mathrm{CO}_{2}$ and the deficit of $\mathrm{O}_{2}$ in the analysed air may be read, after the air being washed in several absorption vessels.

The principle of this equipment is as follows (Fig. 1):

The equipment is built up of a crown-shaped revolving chamber (1) having a quadrate section and manufactured of translucent plastics, in order to vizualize the animal behaviour during the experiment. The chamber (1) has a side-lid hermetically closed, through which the animal is put into the chamber; this is supporte by two legs provided with adjustable clamps and linked to the two rubber rolls (3) of the driving mechanism. The hubb of the revolving chamber (4) is the geometrical and building centre of the chamber; it leads the input-output air and is also the bearing which support the chamber and its appendages. The hubb (4) is an underaggregate (Fig. 2) and comprises the following parts: a central body (5) carring out the function of axle of the chamber, with hollow conducts for the air in and output (6) and threaded slots where the two conducts (7) are screwed up and a groove (8) where a gasket with a hubb-case is fitted up. The hubb-case (9) operates as a guiding chamber for the air admittance in the proper chamber and its going out therefrom through a number of circular (10) and axial conducts (11) excavated into its body. At each $90^{\circ}$ are fixed radially four conducts (12), two of wich being used for the air input and the other two for the air way out; these conducts are also playing the role of spokes. The tightness is secured by the gasket located in the groove (8) and the two side ends (13).

The pump (16) operates the air sucking from the revolving chamber (1) by means of the conduct (7) linked to a gasometer (28) or of the conduct (17) for the external air. The air is then pressed through the "U"-shaped pipes $(23,24)$ into the conducts II and III of the interferometer (25). The pump (18) is sucking the external air, pressing it through the "U"-shaped pipe (22) in the conduct I of the tricompartment chamer of the interferometer (25).

This equipment operates in the following manner: The clamps (14) 


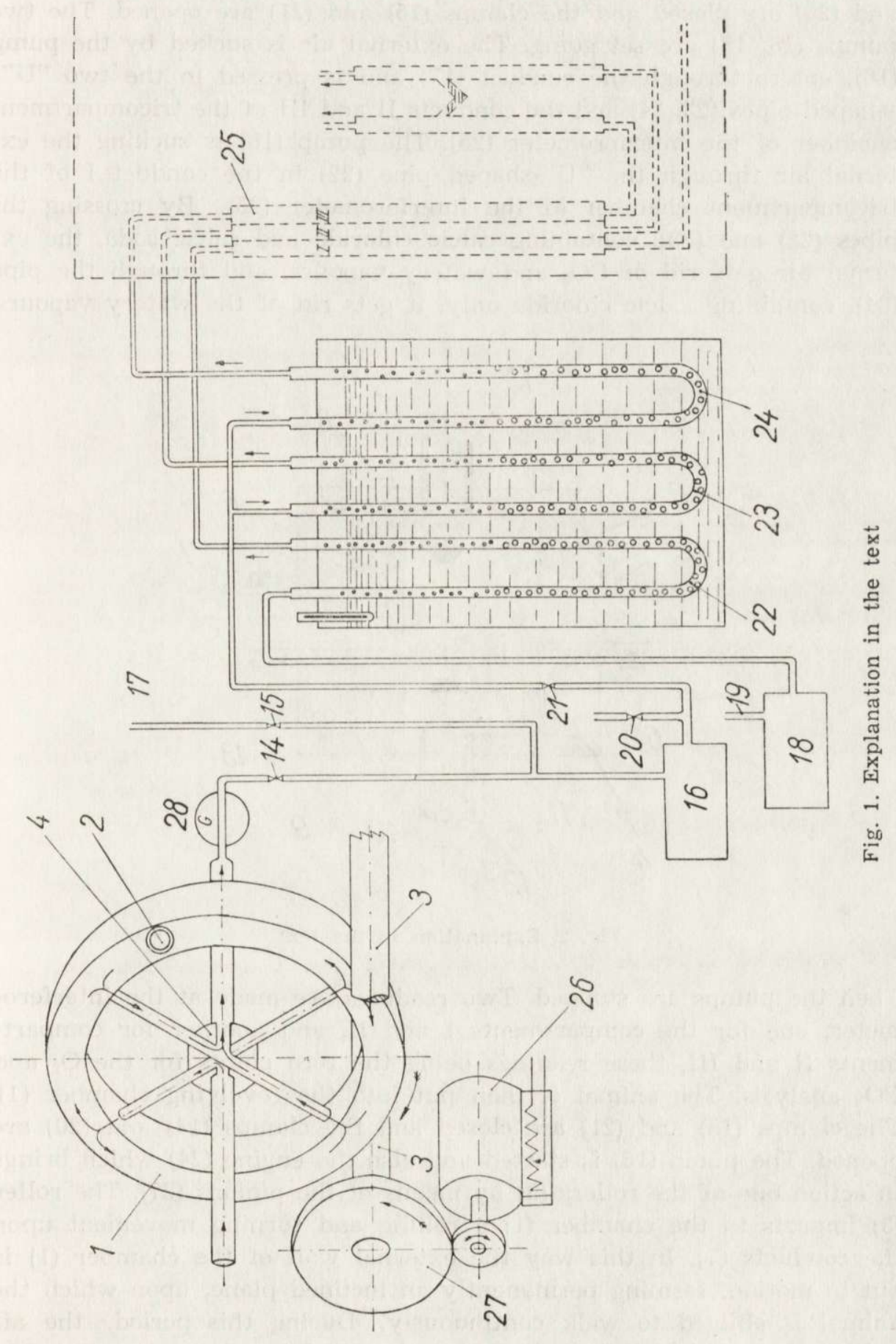


and (20) are closed and the clamps (15) and (21) are opened. The two pumps $(16,18)$ are set going. The external air is sucked by the pump (16), enters through the conduct (17) and is pressed in the two " $U$ "-shaped pipes $(23,24)$ and the conducts II and III of the tricompartment chamber of the interferometer (25). The pump (18) is sucking the external air through the "U"-shaped pipe (22) in the conduct I of the tricompartment chamber of the interferometer (25). By crossing the pipes (22) and (23), containing calcic chloride and calcic soda, the external air gets rid of $\mathrm{CO}_{2}$ and watery vapours, and through the pipe (24), containing calcic chloride only, it gets rid of the watery vapours.

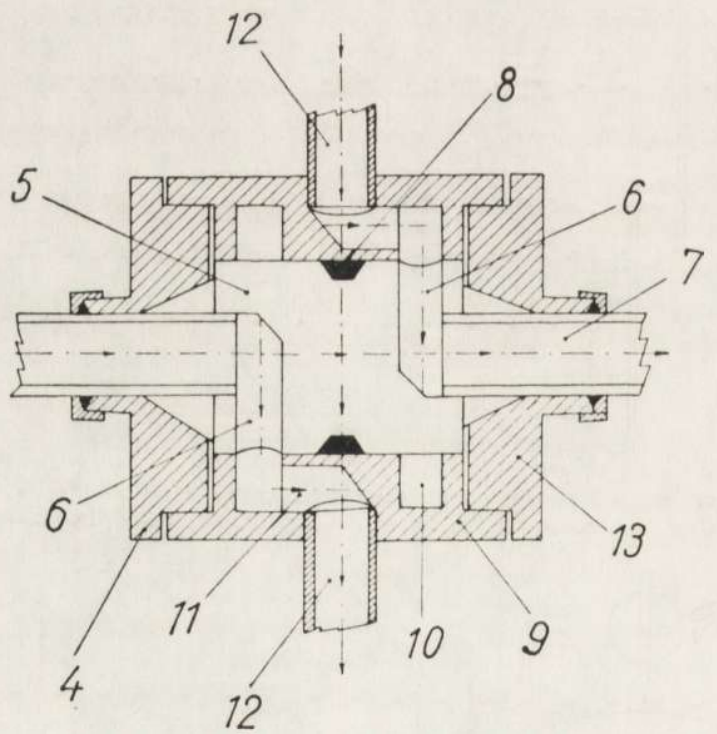

Fig. 2. Explanation in the text.

Then the pumps are stopped. Two readings are made at the interferometer, one for the compartments I and II, and another for compartments II and III, these readings being the zero points for the $\mathrm{O}_{2}$ and $\mathrm{CO}_{2}$ analysis. The animal is then put into the revolving chamber (1). The clamps (15) and (21) are closed and the clamps (14) and (20) are opened. The pump (16) is started and also the engine (24) which brings in action one of the rollers (3) by means of the pinions (27). The roller (3) imparts to the chamber (1) a rolling and turning movement upon the conducts (7). In this way the external wall of the chamber (1) is put in motion, forming permanently an inclined plane, upon which the animal is obliged to walk continuously. During this period, the air volume sucked by the pump (16) is recorded by the gasometer (23), 
located between the chamber and the pump (16). At the very moment when the respiratory gases are to be analysed, the pump (18) is started, introducing the external air which was cleared out of its $\mathrm{CO}_{2}$ and watery vapours when passing through the conduct I of the tricompartment chamber of the interferometer (25). Then the clamps (21) is opened and the clamp (20) closed, the air to by analysed being guided through the pipes (23) and (24), in the compartments II and III of the interferometer, respectively. In the pipe (23) the air gets rid of $\mathrm{CO}_{2}$ and watery vapours generated by the animal, and in the pipe (24) of watery vapours only. The reading of the mobile spectrum deviation in the interferometer, corresponding to the oxygen shortage, is done in the position $1-2$ of the tricompartment chamber, and that corresponding to the $\mathrm{CO}_{2}$ in the position 2-3 of the chamber. When the percentage of the $\mathrm{O}_{2}$ deficit and $\mathrm{CO}_{2}$ amount are known by means of the interferometer and the air amount crossing the revolving chamber (1), by means of the gasometer (28) the energetic metabolism of the animal may be computed, at different times of its strain (effort).

\section{Laboratory working example}

The effort energetic metabolism record in rats

Experimental data

- Animal weight: $237 \mathrm{~g}$,

- Experiment duration: 2 hours,

- Revolving chamber volume (excluding the volume of the animal itself): 17.806 litres,

- Perimeter of the external chamber wall upon which the animal is walking: $213 \mathrm{~cm}$,

- The air flow sucked from the chamber by the pump: $17.8 \mathrm{l} / \mathrm{h}$,

- Atmospheric pressure: $758.3 \mathrm{~mm}$,

- Air temperature in the revolving chamber: $24.4^{\circ} \mathrm{C}$,

- Laboratory air temperature: $23.1^{\circ} \mathrm{C}$,

- Air structure in the chamber at the beginning of the experiment: $\mathrm{CO}_{2}=0.04$ per cent, $\mathrm{O}_{2}=20.93$ per cent

- Air structure in the revolving chamber after two hours effort: $\mathrm{CO}_{2}=1.697$ per cent, $\mathrm{O}_{2}=18.47$ per cent

- Effort dimension: the animal was moving at a $190 \mathrm{~m} / \mathrm{h}$ speed.

From these data the metabolism was calculated as $8,217 \mathrm{kcal} / \mathrm{kg} / \mathrm{h}$.

This experiment has the following advantages: (1) It makes possible to investigate continously the effort energetic metabolism in laboratory animals, at various moments during a effort of varying intensity; (2) It makes additional electrical devices to stir up the animal useless.

Received, February 10, 1968.

Acad. R.S.R.

Institut de Biologie "Traian Savulescu", Spl. Independentei 296, Bucuresti. 
Gheorghe BURLACU \& Gheorghe FAGET

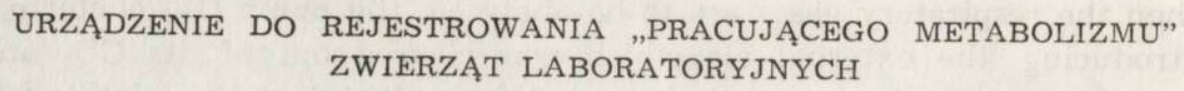

Streszczenie

Skonstruowano i opisano specjalne urządzenie do badania przemiany energii zwierząt laboratoryjnych w czasie wysilku, uzyskanego bez stosowania bodźców elektrycznych.

Zwierzęta umieszczane są w obracającej się komorze. Powietrze doprowadzane jest do niej przez system rur. Powietrze wydychane przez zwierzęta w czasie eksperymentu, zasysane jest przez pompe i kierowane do interferometru, gdzie odczytywany jest procent $\mathrm{CO}_{2}$ i zużycie $\mathrm{O}_{2}$. Potem powietrze zostaje oczyszczone w kilku absorbcyjnych naczyniach. 